\title{
A note on "An economic order quantity (EOQ) for items with imperfect quality and inspection errors"
}

\author{
Lie-Fern Hsu
}

Department of Management, Zicklin School of Business, Baruch College, The City University of New York, One Bernard Baruch Way, BOX B9-240, New York, NY 10010, USA

\begin{tabular}{|c|c|}
\hline AR T I C LE I NFO & A B S TRACT \\
\hline $\begin{array}{l}\text { Article history: } \\
\text { Received 25 February } 2012 \\
\text { Accepted March } 232012 \\
\text { Available online } \\
\text { 24 March } 2012 \\
\end{array}$ & $\begin{array}{l}\text { In a previously published paper by Khan et al. (2011) [Khan, M., Jaber, M.Y., \& Bonney M. } \\
\text { (2011). An economic order quantity (EOQ) for items with imperfect quality and inspection } \\
\text { errors, International Journal of Production Economics, 133, 113-118], we found that there is a } \\
\text { contradiction between the cycle length and the holding cost per cycle. To obtain the cycle length, }\end{array}$ \\
\hline $\begin{array}{l}\text { Keywords: } \\
\text { EOQ } \\
\text { Imperfect quality } \\
\text { Misclassification errors }\end{array}$ & $\begin{array}{l}\text { items. However, for the holding cost per cycle, the authors implicitly assumed that the returned } \\
\text { items were not replaced by good quality items. In this note, we first point out the contradiction. } \\
\text { Then we fix this flaw and develop a corrected EOQ. }\end{array}$ \\
\hline
\end{tabular}

\section{Introduction}

Ever since Harris (1913) presented the famous economic order quantity (EOQ) formula in 1913, many researchers have studied the economic lot size problems extensively by relaxing some of the assumptions of the basic EOQ model. One of the key assumptions of the basic economic order quantity (EOQ) model is that the items received are of perfect quality. However, product quality is not always perfect but is directly affected by the reliability of the production process used. Therefore, the process may deteriorate and produce defectives or poor quality items. Porteus (1986) introduced a model that shows a significant relationship between quality and lot size. Lee and Rosenblatt (1987) addressed the problems of joint control of production cycles or manufacturing quantities, and maintenance by inspections. Schwaller (1988) extended the EOQ model by adding the assumptions that defective items of a known proportion were present in incoming lots and that fixed and variable inspection costs were incurred in finding and removing these defective items. Cheng (1991) proposed an EOQ model with demand-dependent unit production cost and imperfect production processes. Ben-Daya and Hariga (2000) studied the effect of imperfect production processes on the economic lot sizing policy.

* Corresponding author. Tel: 1-646-312-3656, Fax: 1-646-312-3620

E-mail: Lie-Fern.Hsu@baruch.cuny.edu (L.F. Hsu)

(c) 2012 Growing Science Ltd. All rights reserved. doi: $10.5267 / j . i j i e c .2012 .03 .008$ 
Salameh and Jaber (2000) developed an economic order quantity model for the case where a random proportion of the items in a lot are defective. They assumed that received items are subject to $100 \%$ inspection with no inspection errors and that poor-quality items are kept in stock and sold as a single batch at a reduced price at the end of the 100\% inspection process. Goyal and Cárdenas-Barrón (2002) presented a simple approach for determining the economic production quantity of an item with imperfect quality. They showed that near-optimal results are obtained by using the simple approach. The model suggested in their note is easier to implement. Chan et al. (2003) developed an economic production quantity (EPQ) model where the imperfect (not necessarily defective) items could be sold at a lower price and the defective items could be either reworked or rejected.

Papachristos and Konstantaras (2006) discussed the issue of non- shortages in inventory models where the proportion of defective items was a random variable. Speculating on the timing of withdrawing and selling the lot of imperfect items, they proposed an alternative to Salameh and Jaber's (2000) model where defectives were withdrawn at the end of the cycle rather than at the end of $100 \%$ inspection. Eroglu and Ozdemir (2007) extended Salameh and Jaber's (2000) model by allowing shortages to be fully backordered. Maddah and Jaber (2008) corrected a flaw in Salameh and Jaber's (2000) model by using the renewal reward theory. They came up with simpler expressions for the expected profit and the order quantity. Cárdenas-Barrón (2009) developed an EPQ inventory model with planned backorders for determining the economic production quantity and the size of backorders for a single product, which was made in a single-stage manufacturing process that generated imperfect quality products and required that all defective products be reworked in the same cycle. Sana (2010) investigated an EPL (Economic Production Lot size) model in an imperfect production system in which the production facility might shift from an 'in-control' state to an 'out-of-control' state at any random time. For more recent works on inventory models with imperfect quality items, we refer the readers to Khan et al. (2011a).

Salameh and Jaber's (2000) model assumed that there was no human error in the screening process. Raouf et al. (1983) studied human error in inspection. They came up with one of the first inspection plans with misclassifications for multi-characteristic critical components. Duffuaa and Khan (2002) proposed a general inspection plan for quality assurance of critical multi-characteristic components. They extended Raouf et al.'s (1983) inspection plan for the case of six types of misclassification errors, where an inspector could classify an item to be good, rework or scrap. Duffuaa and Khan (2005) carried out a sensitivity analysis to investigate the statistical and economic impact of the several types of misclassification errors on the performance measures of the inspection plan. Yoo et al. (2009) proposed a profit-maximizing EPQ model that incorporated both imperfect production quality and twoway imperfect inspection (i.e., Type I and Type II inspection errors). They also considered rework and salvage in the disposing of screened and returned items, and solved the model optimally and presented numerical sensitivity analyses to provide important managerial insights into practices.

Khan et al. (2011b) extended the work of Salameh and Jaber's (2000) model by assuming that the inspection process was not error-free. They used Raouf et al.'s (1983) approach to suggest that an inspector could incorrectly classify a non-defective item to be defective (a Type I error) or incorrectly classify a defective item to be non-defective (a Type II error). The defective items classified by the inspector and those returned from the market are accumulated and sold at a discounted price at the end of each procurement cycle. The following nomenclature is used in Khan et al.'s (2011b) paper.

$D \quad$ number of units demanded per year

y order size

$c \quad$ unit variable cost

$K \quad$ fixed ordering cost

A a parameter used for simplifying the holding cost

$s \quad$ unit selling price of a non-defective item

$v \quad$ unit selling price of a defective item 
$x \quad$ screening rate

$d \quad$ unit screening cost

$h \quad$ unit holding cost

$T \quad$ cycle length

$m_{1} \quad$ probability of Type I error (classifying a non-defective item as defective)

$m_{2} \quad$ probability of Type II error (classifying a defective item as non-defective)

$p \quad$ probability that an item is defective

$t_{1} \quad$ inspection time in a cycle

$t_{2} \quad$ remaining time in a cycle after the defective items are screened out

$f(p) \quad$ probability density function of $p$

$f\left(m_{1}\right)$ probability density function of $m_{1}$

$f\left(m_{2}\right)$ probability density function of $m_{2}$

$B_{1} \quad$ number of items that are classified as defective in one cycle

$B_{2} \quad$ number of defective items that are returned from the market in one cycle

$c_{a} \quad$ cost of accepting a defective item

$c_{r} \quad$ cost of rejecting a non-defective item

Fig. 1 shows the behavior of the inventory level over time. Khan et al. (2011b) stated, "To avoid shortage, it is assumed that the number of non-defective items is at least equal to the adjusted demand, that is the sum of the actual demand and items that are replaced for the ones returned $\left(\mathrm{pm}_{2} y\right)$ from the market over T." Based on the above statement, the adjusted demand is $D^{\prime}=D+B_{2} / T$. By definition, the cycle length $T=\left(y-B_{1}\right) / D^{\prime}$. Substituting $D^{\prime}=D+B_{2} / T$ and solving the equation, we have

$$
T=\frac{\left(y-B_{1}-B_{2}\right)}{D}=\frac{y(1-p)\left(1-m_{1}\right)}{D} .
$$

The cycle length is the same as Eq. (1) in Khan et al. (2011b). From Fig. 1 the holding cost for a cycle can be written as

$$
H C=h\left\{\frac{\left(y-Z_{1}\right) t_{1}}{2}+Z_{1} t_{1}+\frac{Z_{2} t_{2}}{2}\right\}+h\left(\frac{B_{2} T}{2}\right) .
$$

By replacing $B_{2}$ with $y p m_{2}, Z_{2}$ with $Z_{1}-B_{1}, Z_{1}$ with $y-D t_{1}$, $t_{1}$ with $y / x$, and $t_{2}$ with $Z_{2} / D$, Khan et al. (2011b) obtained

$H C=\frac{h y^{2}}{2}\left(\frac{2}{x}-\frac{D}{x^{2}}+\frac{A^{2}}{D}\right)+\frac{h}{2}\left(y p m_{2} T\right)$,

where $A=1-D / x-\left(m_{1}+p\right)+p\left(m_{1}+m_{2}\right)$.

Note that based on the above equation,

$t_{1}+t_{2}=\frac{y\left(1-\left(m_{1}+p\right)+p\left(m_{1}+m_{2}\right)\right)}{D}$. 


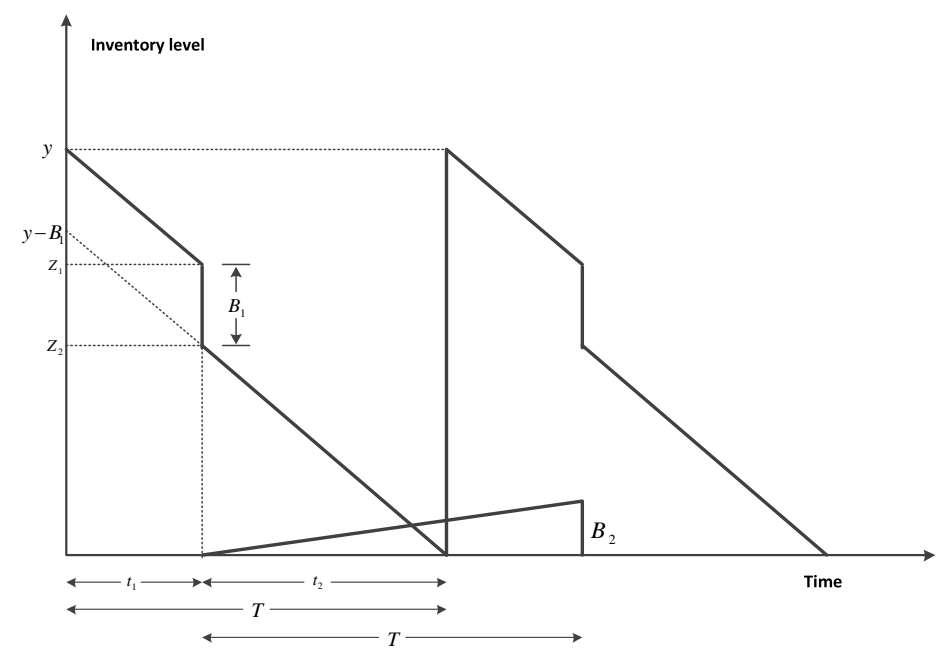

Fig. 1. Behavior of the inventory level over time.

From Fig. $1, t_{1}+t_{2}=T$. However, from Eq. (1) and Eq. (2), we see that $t_{1}+t_{2} \neq T$. This shows the contradiction in Khan et al.'s (2011b) mathematical model. We will fix the problem in the next section and develop a corrected EOQ.

\section{The corrected model}

If the returned items from the market are replaced with good items, then the inventory will be depleted at a rate of $D^{\prime}=D+B_{2} / T=D\left(y-B_{1}\right) /\left(y-B_{1}-B_{2}\right)$. To obtain the holding cost per cycle, one should replace $Z_{1}$ with $y-D^{\prime} t_{1}$ and $t_{2}$ with $Z_{2} / D^{\prime}$. However, doing this will make the equation very complicated. An easier way to obtain the holding cost per cycle is to get rid of $Z_{1}, Z_{2}$, and $t_{2}$. This can be shown as follows.

$$
\begin{aligned}
H C & =h\left\{\frac{\left(y-Z_{1}\right) t_{1}}{2}+Z_{1} t_{1}+\frac{Z_{2} t_{2}}{2}\right\}+h\left(\frac{B_{2} T}{2}\right)=\frac{h}{2}\left\{y t_{1}+Z_{1} t_{1}+Z_{2} t_{2}\right\}+h\left(\frac{B_{2} T}{2}\right) \\
& =\frac{h}{2}\left\{\left(y-B_{1}\right) t_{1}+B_{1} t_{1}+\left(Z_{2}+B_{1}\right) t_{1}+Z_{2} t_{2}\right\}+h\left(\frac{B_{2} T}{2}\right)=\frac{h}{2}\left\{2 B_{1} t_{1}+\left(y-B_{1}\right) t_{1}+Z_{2} T\right\}+h\left(\frac{B_{2} T}{2}\right) \\
& =\frac{h}{2}\left\{2 B_{1} t_{1}+\left(y-B_{1}\right) t_{1}+\left(y-D^{\prime} t_{1}-B_{1}\right) T\right\}+h\left(\frac{B_{2} T}{2}\right) \\
& =\frac{h}{2}\left\{2 B_{1} t_{1}+\left(y-B_{1}\right) T+\left(y-B_{1}\right) t_{1}-D^{\prime} t_{1} T\right\}+h\left(\frac{B_{2} T}{2}\right) \\
& =\frac{h}{2}\left\{2 B_{1} t_{1}+\left(y-B_{1}\right) T+\left(y-B_{1}\right) t_{1}-D \frac{\left(y-B_{1}\right)}{\left(y-B_{1}-B_{2}\right)} t_{1} \frac{\left(y-B_{1}-B_{2}\right)}{D}\right\}+h\left(\frac{B_{2} T}{2}\right) \\
& =h\left\{B_{1} t_{1}+\frac{\left(y-B_{1}\right) T}{2}\right\}+h\left(\frac{B_{2} T}{2}\right) .
\end{aligned}
$$

Eq. (3) can be explained intuitively. The $B_{1}$ items classified as defective by an inspector in one cycle are withdrawn from the inventory at time $t_{1}$, thus incurring a holding cost of $h B_{1} t_{1}$. The remaining 
$\left(y-B_{1}\right)$ items are depleting constantly through the cycle of length $T$. Thus, the corresponding holding cost will be $h\left(y-B_{1}\right) T / 2 . B_{2}$ items are returned from the market continuously through the cycle, and therefore incur a holding cost of $h B_{2} T / 2$. Substituting $t_{1}$ by $y / x, B_{1}$ by $y(1-p) m_{1}+y p\left(1-m_{2}\right), B_{2}$ by ypm $_{2}$, and $T$ by $y(1-p)\left(1-m_{1}\right) / D$, the holding cost per cycle is given by

$$
H C=h\left\{\frac{y^{2}}{x}\left\{(1-p) m_{1}+p\left(1-m_{2}\right)\right\}+\frac{y^{2}\left\{1-\left(m_{1}+p\right)+p\left(m_{1}+2 m_{2}\right)\right\}(1-p)\left(1-m_{1}\right)}{2 D}\right\} .
$$

The total cost per cycle is

$$
\begin{aligned}
C & =K+c y+d y+c_{r}(1-p) y m_{1}+c_{a} \text { pym }_{2} \\
& +h\left\{\frac{y^{2}}{x}\left\{(1-p) m_{1}+p\left(1-m_{2}\right)\right\}+\frac{y^{2}\left\{1-\left(m_{1}+p\right)+p\left(m_{1}+2 m_{2}\right)\right\}(1-p)\left(1-m_{1}\right)}{2 D}\right\}
\end{aligned}
$$

and the total profit per cycle is

$$
\begin{aligned}
T P(y) & =s y(1-p)\left(1-m_{1}\right)+\operatorname{sypm}_{2}+v y(1-p) m_{1}+v y p-\left\{K+c y+d y+c_{r}(1-p) y m_{1}+c_{a} \text { pym }_{2}\right\} \\
& -h\left\{\frac{y^{2}}{x}\left\{(1-p) m_{1}+p\left(1-m_{2}\right)\right\}+\frac{y^{2}\left\{1-\left(m_{1}+p\right)+p\left(m_{1}+2 m_{2}\right)\right\}(1-p)\left(1-m_{1}\right)}{2 D}\right\} .
\end{aligned}
$$

Let $A_{1}=\left\{1-\left(m_{1}+p\right)+p\left(m_{1}+2 m_{2}\right)\right\}(1-p)\left(1-m_{1}\right)$, so the expected total profit per cycle is

$$
\begin{aligned}
E[T P(y)]= & s y(1-E[p])\left(1-E\left[m_{1}\right]\right)+s y E[p] E\left\{m_{2}\right]+v y(1-E[p]) E\left[m_{1}\right]+v y E[p] \\
& -K-c y-d y-c_{r} y(1-E[p]) E\left[m_{1}\right]-c_{a} y E[p] E\left[m_{2}\right] \\
& -h\left[\frac{y^{2}}{x}\left\{(1-E[p]) E\left[m_{1}\right]+E[p]\left(1-E\left[m_{2}\right]\right)\right\}+\frac{y^{2} E\left[A_{1}\right]}{2 D}\right],
\end{aligned}
$$

and the expected cycle length is

$$
E[T]=\frac{y(1-E[p])\left(1-E\left[m_{1}\right]\right)}{D} .
$$

Using the renewal reward theorem, the expected annual profit is

$$
\begin{aligned}
E[T P U(y)]= & \frac{E[T P(y)]}{E[T]}=s D+\frac{s D E[p] E\left[m_{2}\right]}{(1-E[p])\left(1-E\left[m_{1}\right]\right)}+\frac{v D E\left[m_{1}\right]}{\left(1-E\left[m_{1}\right]\right)} \\
& +\frac{v D E[p]}{(1-E[p])\left(1-E\left[m_{1}\right]\right)}-\frac{D\left(\frac{K}{y}+c+d+c_{r}(1-E[p]) E\left[m_{1}\right]+c_{a} E[p] E\left[m_{2}\right]\right)}{(1-E[p])\left(1-E\left[m_{1}\right]\right)} \\
& -h D \frac{y\left\{(1-E[p]) E\left[m_{1}\right]+E[p]\left(1-E\left[m_{2}\right]\right)\right\}}{x(1-E[p])\left(1-E\left[m_{1}\right]\right)}-h \frac{y E\left[A_{1}\right\}}{2(1-E[p])\left(1-E\left[m_{1}\right]\right)} .
\end{aligned}
$$


The first derivative of Eq. (9) is

$$
\begin{aligned}
& \frac{\partial E[T P U(y)]}{\partial y}=\frac{K D}{y^{2}(1-E[p])\left(1-E\left[m_{1}\right]\right)}-h D \frac{\left\{(1-E[p]) E\left[m_{1}\right]+E[p]\left(1-E\left[m_{2}\right]\right)\right\}}{x(1-E[p])\left(1-E\left[m_{1}\right]\right)} \\
& -h \frac{E\left[A_{1}\right]}{2(1-E[p])\left(1-E\left[m_{1}\right]\right)},
\end{aligned}
$$

and the second derivative is

$$
\frac{\partial^{2} E[T P U(y)]}{\partial y^{2}}=-\frac{2 K D}{y^{3}(1-E[p])\left(1-E\left[m_{1}\right]\right)} .
$$

Since $K>0, D>0,0<E[p]<1$, and $0<E\left[m_{1}\right]<1$, we have $\frac{\partial^{2} E[T P U(y)]}{\partial y^{2}}<0$ for every $y>0$, which implies that there exists a unique solution of $y$ that maximizes the expected annual profit, which is given by

$$
y^{*}=\sqrt{\frac{2 K D}{h\left\{\frac{2 D}{x}\left\{(1-E[p]) E\left[m_{1}\right]+E[p]\left(1-E\left[m_{2}\right]\right)\right\}+E\left[A_{1}\right]\right\}}} .
$$

Note that

$$
\begin{aligned}
A_{1}= & \left\{1-\left(m_{1}+p\right)+p\left(m_{1}+2 m_{2}\right)\right\}(1-p)\left(1-m_{1}\right)=1-2\left(m_{1}+p\right)+4 p m_{1}+2 p m_{2}\left(1-m_{1}\right) \\
& +m_{1}{ }^{2}(1-2 p)+p^{2}\left(1-2 m_{1}-2 m_{2}+2 m_{1} m_{2}+m_{1}{ }^{2}\right) .
\end{aligned}
$$

If $p, m_{1}$, and $m_{2}$ are independent with each other, then we have

$$
\begin{aligned}
E\left[A_{1}\right]= & 1-2\left(E\left[m_{1}\right]+E[p]\right)+4 E[p] E\left[m_{1}\right]+2 E[p] E\left[m_{2}\right]\left(1-E\left[m_{1}\right]\right) \\
& +E\left[m_{1}^{2}\right](1-2 E[p])+E\left[p^{2}\right]\left(1-2 E\left[m_{1}\right]-2 E\left[m_{2}\right]+2 E\left[m_{1}\right] E\left[m_{2}\right]+E\left[m_{1}^{2}\right]\right) .
\end{aligned}
$$

Note that if there are no inspection errors, then Eq. (10) reduces to

$$
y^{*}=\sqrt{\frac{2 K D}{h} \frac{1}{\left\{\frac{2 D}{x} E[p]+1-2 E[p]+E\left[p^{2}\right]\right\}}}=\sqrt{\frac{2 K D}{h} \frac{1}{\left\{\frac{2 D}{x} E[p]+E\left[(1-p)^{2}\right]\right\}}},
$$

which is the same as the corrected model (Eq. (7) on page 810) in Maddah and Jaber (2008).

\section{Numerical Examples}

Khan et al. (2011b) lot size quantity was given as

$$
y^{* *}=\sqrt{\frac{2 K D}{h E[p] E\left[m_{2}\right](1-E[p])\left(1-E\left[m_{1}\right]\right)+h D\left(\frac{2}{x}-\frac{D}{x^{2}}+\frac{E\left[A^{2}\right]}{D}\right)}},
$$


where

$$
\begin{aligned}
& \begin{aligned}
A=1- & D / x-\left(m_{1}+p\right)+p\left(m_{1}+m_{2}\right)
\end{aligned} \\
& \begin{aligned}
E\left[A^{2}\right]= & 1-2 \frac{D}{x}\left(1-E[p]-E\left[m_{1}\right]+E[p]\left(E\left[m_{1}\right]+E\left[m_{2}\right]\right)\right)+\frac{D^{2}}{x^{2}}-2\left(E[p]+E\left[m_{1}\right]\right) \\
& +4 E[p] E\left[m_{1}\right]+2 E[p] E\left[m_{2}\right]
\end{aligned} \\
& +E\left[p^{2}\right]\left(1-2 E\left[m_{1}\right]-2 E\left[m_{2}\right]+E\left[m_{1}^{2}\right]+2 E\left[m_{1}\right] E\left[m_{2}\right]+E\left[m_{2}^{2}\right]\right) \\
& +E\left[m_{1}^{2}\right](1-2 E[p])-2 E[p] E\left[m_{1}\right] E\left[m_{2}\right] .
\end{aligned}
$$

then, we have

$$
\begin{aligned}
& E[p]=\int_{0}^{\beta} p f(p) d p=\int_{0}^{\beta} \frac{p}{\beta} d p=\frac{\beta}{2}, \\
& E\left[p^{2}\right]=\int_{0}^{\beta} p^{2} f(p) d p=\int_{0}^{\beta} \frac{p^{2}}{\beta} d p=\frac{\beta^{2}}{3}, \\
& E\left[m_{1}\right]=\frac{\lambda}{2}, E\left[m_{1}{ }^{2}\right]=\frac{\lambda^{2}}{3}, E\left[m_{2}\right]=\frac{\eta}{2}, E\left[m_{2}{ }^{2}\right]=\frac{\eta^{2}}{3} .
\end{aligned}
$$

Specifically, if

1) $D=50000, x=175200, K=100, h=5, E[p]=E\left[m_{1}\right]=E\left[m_{2}\right]=0.35$, we have

$y^{*}=1890.98, y^{* *}=1770.88$. The error is $(1890.98-1770.88) / 1890.98=6.35 \%$.

2) $D=50000, x=175200, K=300, h=5, E[p]=E\left[m_{1}\right]=E\left[m_{2}\right]=0.35$, we have $y^{*}=3275.27, y^{* *}=3067.26$. The error is (3275.27-3067.26)/3275.27 $=6.35 \%$.

3) $D=100000, x=350000, K=100, h=5, E[p]=E\left[m_{1}\right]=E\left[m_{2}\right]=0.35$, we have $y^{*}=2673.54, y^{* *}=2503.83$. The error is $(2673.54-2503.83) / 2673.54=6.35 \%$.

The above three examples show that the errors could be quite significant under different parameter sets.

\section{Conclusions}

In this technical note we point out a contradiction in Khan et al.'s (2011b) mathematical model. We rectify the flaw and develop a corrected model. Numerical examples show that the errors could be quite significant under different parameter sets.

\section{References}

Ben-Daya, M., \& Hariga, M. (2000). Economic lot scheduling problem with imperfect production processes. Journal of the Operational Research Society, 51, 875-881. 
Cárdenas-Barrón, L.E., (2009). Economic production quantity with rework process at a single-stage manufacturing system with planned backorders. Computers and Industrial Engineering, 57, 1105-1113.

Chan, W.M., Ibrahim, R.N., \& Lochert, P.B., (2003). A new EPQ model: Integrating lower pricing, rework and reject situations. Production Planning and Control, 14, 588-595.

Cheng, C. E., 1991. An economic order quantity model with demand-dependent unit production cost and imperfect production processes. IIE Transactions, 23, 23-28.

Duffuaa, S.O., \& Khan, M. (2002). An optimal repeat inspection plan with several classifications. Journal of the Operational Research Society, 53, 1016-1026.

Duffuaa, S.O., \& Khan, M. (2005). Impact of inspection errors on the performance measures of a general repeat inspection plan. International Journal of Production Research, 43, 4945-4967.

Eroglu, A., \& Ozdemir, G. (2007). An economic order quantity model with defective items and shortages. International Journal of Production Economics, 106, 544-549.

Goyal, S. K., \& Cárdenas-Barrón, L. E. (2002). Note on: economic production quantity model for items with imperfect quality - a practical approach. International Journal of Production Economics, 77, 85-87.

Harris, F.W. (1913). How many parts to make at once. Factory. The Magazine of Management, 10 (2), 135-136, 152.

Khan, M., Jaber, M.Y., Guiffrida, A.L., \& Zolfaghari, S. (2011a). A review of the extensions of a modified EOQ model for imperfect quality items. International Journal of Production Economics, 132, 1-12.

Khan, M., Jaber, M.Y., \& Bonney, M. (2011b). An economic order quantity (EOQ) for items with imperfect quality and inspection errors. International Journal of Production Economics, 133, 13118.

Lee, H. L., \& Rosenblatt, M. J., (1987). Simultaneous determination of production cycles and inspection schedules in a production system. Management Science, 33, 1125-1137.

Maddah, B., \& Jaber, M.Y. (2008). Economic order quantity for items with imperfect quality: revisited. International Journal of Production Economics, 112, 808-815.

Papachristos, S., \& Konstantaras, I. (2006). Economic ordering quantity models for items with imperfect quality. International Journal of Production Economics, 100, 148-154.

Porteus, E. L. (1986). Optimal lot sizing, process quality improvement and setup cost reduction. Operations Research, 34, 137-144.

Raouf, A., Jain, J.K., \& Sathe, P.T. (1983). A cost-minimization model for multicharacteristic component inspection. IIE Transactions, 15, 187-194.

Salameh, M.K., \& Jaber, M.Y. (2000). Economic production quantity model for items with imperfect quality. International Journal of Production Economics, 64, 59-64.

Sana, S.S. (2010). An economic production lot size model in an imperfect productio system. European Journal of Operational Research, 201, 158-170.

Schwaller, R. L., (1988). EOQ under inspection costs. Production and Inventory Management, 29, 2224.

Yoo, S.H., Kim, D., \& Park, M.S., (2009). Economic production quantity model with imperfect-quality items, two-way imperfect inspection and sales return. International Journal of Production Economics, 121, 255-265. 